\title{
Educação Ambiental na prática pedagógica dos docentes do curso de Pedagogia
}

\author{
Environmental Education in the pedagogical \\ practice of pedagogy teachers
}

\author{
Joseane Patrícia dos Santos ${ }^{1}$ \\ Zélia Maria Soares Jófili \\ Gilvaneide Ferreira de Oliveira ${ }^{3}$
}

\section{Resumo}

Este trabalho é resultado de uma pesquisa em nível de mestrado que foi desenvolvida com docentes do curso de pedagogia de uma universidade pública que teve como objetivo investigar as contribuições do curso de licenciatura em Pedagogia para a formação do professor como educador socioambiental, tomando como base as concepções e práticas dos docentes do referido curso. Este artigo é parte dos resultados apresentados na dissertação, que tem por objetivo investigar as contribuições da inserção da EA na prática docente no curso de Licenciatura em Pedagogia de uma IES para a formação do professor como educador socioambiental. Para a realização desta pesquisa, foram adotados os procedimentos metodológicos de uma abordagem qualitativa, e para a análise alguns dos pressupostos teóricos e metodológicos da análise de conteúdo de Bardin (1977). Os sujeitos deste estudo foram os docentes do referido curso. Como resultados verificamos que as práticas pedagógicas analisadas possibilitam oportunidades de reflexão crítica sobre as questões socioambientais, contribuindo para a formação de um pedagogo com um olhar mais sensível à EA.

Palavras-chave: Formação de professores; Educação Ambiental; Concepções e práticas pedagógicas.

\section{Abstract}

This work is the result of research at Masters level which was developed with teachers from teaching at a public university that aims to investigate the contributions of the degree course in pedagogy for teacher education as environmental educator, based on the conceptions and practices of teachers in that course. This article is a sample of the results presented in this dissertation, which aims to investigate the contributions of the introduction of EE in practice teaching in the course of Pedagogy of an IES for teacher training as environmental educator. For this research, the methodological procedures were adopted a qualitative approach, and to analyze some of the theoretical and methodological content analysis of Bardin (1977). The subjects of this study were the teachers of that course. The results found that teaching practices analyzed provide opportunities for critical reflection on social and environmental issues, contributing to the formation of a teacher with a more sensitive EA.

Keywords: Teacher training; Environmental Education Concepts and pedagogical practices.

\footnotetext{
${ }^{1}$ Pedagoga, Mestre em Ensino de Ciências pelo PPGEC/UFRPE. Professora da SEDUC/PE | joseanepatricia1986@gmail.com

2 Professora do PPGEC/UFRPE | jofili@gmail.com

${ }^{3}$ Professora do Departamento de Educação/UFRPE | gil@ded.ufrpe.br
} 


\section{Introdução}

Os constantes debates relacionados às responsabilidades e cuidados com os recursos ambientais têm despertado a sensibilização dos diversos setores sociais em torno da educação ambiental. Nos últimos anos, os grandes desmatamentos realizados a fim de favorecer as práticas de agropecuária, a poluição de rios e córregos por instalações industriais que eliminam seus resíduos de forma indiscriminada, a emissão de gases tóxicos jogados na atmosfera pela crescente frota de veículos, a extração excessiva de recursos minerais, e a sobrevivência de muitas famílias através de coleta de resíduos para se alimentarem, enquanto outras consomem além do que realmente necessitam, são exemplos de impactos socioambientais decorrentes da ação humana.

Os fatos que refletem o espírito consumista, fortemente marcado nos anseios dos indivíduos, cada vez mais impulsionados pela mídia publicitária, remetem à ideia de que nas relações sociais "vale mais quem tem, quem gasta", iludindo-nos com a proposta de que: quem tem mais, é quem pode. Assim, o interesse individual pode se sobrepor ao da coletividade.

Esses fatos demonstram uma crescente necessidade de tratarmos questões socioambientais de forma crítica, reflexiva e transformadora, inclusive nos contextos escolares. No entanto, para que isso seja desenvolvido nesses contextos, é necessária e urgente a formação de profissionais da educação comprometidos com a transformação desse quadro de descaso com o meio ambiente, ou seja, educadores competentes e conscientes do seu papel socioambiental. Essa necessidade intensifica a responsabilidade das instituições de ensino superior em formar tais profissionais, pois é percebida a falta de uma formação docente voltada para uma perspectiva socioambiental que vise à formação de sujeitos críticos e reflexivos, preocupados com a transformação dessa realidade.

Como preconizado na Conferência de Tbilisi (1978), especificamente no que se refere à Educação Ambiental nas universidades, a recomendação no 13 da citada Conferência estabelece que a formação docente deve romper com os modelos tradicionais de educação, encorajar a aceitação da interdisciplinaridade para a solução dos problemas socioambientais em todas as áreas do conhecimento, favorecer o desenvolvimento de conceitos e de materiais didáticos apropriados às características locais e estabelecer parcerias locais, nacionais e internacionais, no sentido de promover a formação humana e a troca de experiências.

Nesse sentido, os cursos de formação de professores para os anos iniciais do Ensino Fundamental devem se voltar para a realização de reflexões críticas acerca da formação do educador ambiental, repensando as questões ambientais para além da preservação dos recursos naturais e visando a um desenvolvimento sustentável com justiça social.

Na perspectiva de uma formação docente voltada para as questões socioambientais, propomos que essa esteja aliada a um amplo processo de reflexão sobre a formação do sujeito como educador socioambiental de acordo com os seguintes pilares: reflexão, ação, criticidade, saberes e experiências, consubstanciando para formação integral do sujeito, como caracterizada nos discursos de Gadotti (2005), Loureiro (2004), Pimenta (2004), Reigota (2003), Tardif (2002), Freire (2002), Sucena (1998), Medina (1996) e Nóvoa (1995), entre outros. 
Diante dessas inquietações acerca da educação socioambiental e da formação docente, questionamo-nos sobre até que ponto as práticas didático-pedagógicas dos professoresformadores revelam possíveis contribuições para a formação da docência numa perspectiva socioambiental, crítico-reflexiva e transformadora. Nesta perspectiva, propomo-nos, neste estudo, investigar: as contribuições da inserção da EA na prática docente no curso de Licenciatura em Pedagogia de uma IES para a formação do professor como educador socioambiental.

\section{Reflexões acerca da Educação Ambiental}

Ao tratarmos das reflexões acerca da Educação Ambiental (EA), constituída num percurso histórico marcado por transformações paradigmáticas, priorizamos duas grandes correntes da EA, embora existam outras.

A primeira corrente caracteriza-se por ser simplista e fragmentada tendo sua base teórica ancorada no pensamento de Descartes (1998). Apoia-se num paradigma que considera o indivíduo como o centro de todas as coisas, tendo a natureza como algo a ser dominado a seu favor, vendo-se dissociado e superior a ela. Em relação a isso, Carvalho (2004) diz que esse indivíduo passa por algumas formas de dissociação da natureza: primeiro ele a vê como uma forma de dominação, depois tende a vê-la de forma romântica. Embora Descartes (1998) não tenha discutido, diretamente, questões ambientais, o seu pensamento serviu de base para o paradigma que fundamenta a Educação Ambiental conservadora.

A segunda corrente, caracterizada pelo pensamento de liberdade, ética e cidadania, tem por base teórica as ideias de Espinosa (2005), ressaltando que nem Descartes nem Espinosa trataram em seus textos diretamente da EA.

Discorreremos, a seguir, sobre o desenvolvimento dessas duas correntes de EA no contexto brasileiro, bem como suas consequências no que se refere às questões socioambientais.

Para Grün (2006) as consequências do pensamento cartesiano são enormes para os desdobramentos da nossa relação com a natureza - a objetividade cartesiana fez com que "perdêssemos" a possibilidade de pensar historicamente e colocou o homem europeu e branco na posição de "dono e senhor" da natureza.

Compartilhando da ideia de Grün (2006), consideramos que a modernidade parte de um esquecimento de qualquer vínculo com a "tradição". Em seu trabalho Grün (2006) categoriza o termo "tradição" como um conjunto de elementos que constituem a nossa historicidade.

O Iluminismo, que foi uma época em que Deus deixou de ser o centro e o homem passou a estar no centro de todas as coisas, atacou bruscamente essa tradição. Segundo Grün (2006), esse ataque começa com Francis Bacon no séc.XVI, pois para ele a tradição científica, filosófica ou verbal precisaria ser descartada para que se pudesse chegar a uma ciência nova e, após Bacon, passamos a viver em um presente puro, liberto da historicidade. Descartes, no séc. XVII deu continuidade a esse processo.

No "Discurso do Método", Descartes (1998) apresenta sua opinião contrária ao Humanismo e à tradição, pois para ele os costumes e a cultura não podem ser usados para afirmar ou determinar a veracidade de uma coisa, pois, tanto na cultura como na filosofia, há uma divergência muito grande de opiniões: 
[...] assim, o maior benefício que daí tirei foi que, percebendo uma série de coisas que, entretanto, nos parecem aceitas e aprovadas comumente por outros grandes povos, aprendi a não confiar muito em nada do que me fora incutido somente pelo exemplo e pelo hábito, e, desse modo, livrei-me gradativamente de muitos erros capazes de ouvir a voz da razão (DESCARTES, 1998, p. 37-38).

Tendo por princípio o "eu" no centro do conhecimento, Descartes (1996) busca o estabelecimento de um método que elimine as diversidades de visões e o potencial para o erro. Esse método pode ser explicado em quatro regras simples:

O primeiro preceito era o de jamais aceitar alguma coisa como verdadeira que não soubesse ser evidente como tal, isto é, de evitar cuidadosamente a precipitação e a prevenção, e de nada incluir em meus juízos que não se apresentasse tão clara e tão distintamente a meu espírito que eu não tivesse nenhuma chance de colocar em dúvida.

O segundo, o de dividir cada uma das dificuldades que eu examinasse em tantas partes quantas possíveis e quantas necessárias fossem para melhor resolvê-las.

O terceiro, o de conduzir por ordem meus pensamentos, a começar pelos objetos mais simples e mais fáceis de serem conhecidos, para galgar, pouco a pouco, como que por graus, até o conhecimento dos mais complexos e, inclusive, pressupondo uma ordem entre os que não se precedem naturalmente uns aos outros.

E o último, o preceito de fazer em toda parte enumerações tão completas e revisões tão gerais que eu tivesse a certeza de nada ter omitido (Ibid., p. 44-475).

Esse método que tem a razão, o "eu" como centro do conhecimento, deixa de lado a cultura, a historicidade do sujeito, suas experiências, seus sentidos e significados em sua relação com o mundo. O referido método também proporcionou um grande avanço na ciência, conquistou uma profunda aceitação nas modernas instituições educacionais da sua época, sendo perpetuado nas décadas posteriores.

O princípio do método de Descartes, baseado na expressão "penso, logo existo", fez surgir o sujeito moderno "O qual a educação moderna tentará reproduzir" (GRÜN, 2006, p.70). Um sujeito destituído de sentido, de integração com o mundo, um sujeito que "ainda não tem um lugar" (GRÜN, 2006, p.70). Esse sujeito que mantém com a natureza uma relação distinta, de não pertencimento e dominação: "compreendi que era uma substância cuja essência ou natureza consiste apenas no pensar e que para ser não necessita de um lugar, nem depende de qualquer coisa material" (DESCARTES, 1996, p. 56).

Nesse sentido, nos dias atuais, é um desafio da filosofia da educação ambiental "situar o sujeito, ancorá-lo a um sentido unificado de lugar" (GRÜN, 2006, p.70), para que a sua localização, então, produza significados.

Pelas características acima apresentadas e compartilhando do pensamento de outros autores como Berman (1985), Capra (2006), Capra et al. (2006), Grün (2006) e Santos e Oliveira (2011), que trazem em suas obras críticas a Descartes (1995), consideramos o pensamento cartesiano reducionista, pois este não considera a ligação sistêmica e complexa das coisas. 
Embora reconhecendo a importância do paradigma cartesiano na construção do conhecimento e seu papel na fundamentação da primeira corrente de EA caracterizada por Santos e Oliveira (2011) como sendo conservadora, reducionista, simplista e fragmentada, o consideramos inadequado no que se refere ao entendimento das questões socioambientais, a construção de práticas contextualizadas e voltadas para a formação do cidadão consciente do seu papel ambiental e das demandas socioambientais do presente século.

O paradigma socioambiental, crítico-reflexivo e transformador que tem por características a integração do homem com natureza, o pensamento sistêmico e o olhar holístico, representa a segunda corrente de EA, tendo por princípio o pensamento de liberdade, ética e cidadania, baseado nas ideias de Espinosa (2005).

Espinosa (2005) propõe-nos pensar integrados com a natureza. Traz a noção do todo que está contido nas partes, e que não deixa de ser o todo. O sujeito, nessa concepção, é uma parte individualizada e autônoma da natureza e sua relação com ela tem que ser de respeito e de interação, pois a destruição de uma se reflete na outra. Além disso, "se uma parte do todo se anulasse, tudo se aniquilaria" (FERREIRA, 1997, p. 535). Essa ideia sistêmica, ao analisar o sujeito e a natureza, também é apresentada por Capra (2006).

Nesse sentido, a integração da parte com o todo torna Espinosa (2005) mais próximo dos problemas socioambientais contemporâneos e, por isso, segundo Ferreira (1997), seu pensamento tem sido usado como fundamento da ética ambiental. Um ponto importante trazido pelo pensamento de Espinosa (2005) é que o homem faz parte do todo e não é a causa nem o centro do mundo, "mas faz parte de uma rede composta de infinitas outras coisas que estabelecem, entre si, necessidades, causalidades e implicações, que o afetam direta ou indiretamente" (SAWAIA, 2006, p. 82).

Tendo em vista essa integração entre homem e natureza, Espinosa (2005) apresenta duas ideias:

Uma, que o homem é energia e movimento dirigidos à obtenção da felicidade, tendo, portanto, no desejo de liberdade a essência de sua vida. Outra, que ele é perfeição e, assim, não pode conter a destruição de si mesmo, e que nenhum poder negativo entra na sua constituição. Ao contrário, o homem tem em si a potência de se manter no mesmo estado ou elevar-se a uma melhor força de existir. A esse esforço existencial para se preservar, Espinosa designa de conatus, indicando que todos somos sempre conscientes dele, qualquer que seja o nível de consciência e de lucidez em que nos situamos (Ética III, proposição VII). Então, a redução ou bloqueio do conatus só pode vir de fora, da maneira como a liberdade de existir de cada um é afetada nos encontros com outros corpos.

Quando o homem sente que aumenta a sua potência (liberdade) de existir, é afetado por sentimentos de alegria; se essa capacidade é reprimida, ele é dominado por paixões tristes (tristeza, medo, humilhação), (SAWAIA, 2006, p. 83).

Para Espinosa (2005, apud SAWAIA, 2006) o primeiro é o estado de maior perfeição, porque está associado às afecções ativas e à servidão. Ele identifica felicidade e liberdade, colocando-as no reino das necessidades humanas básicas e da ética. Partindo dessas duas ideias de Espinosa (2005), é possível chegar à conclusão de que o homem luta por sua escravidão como se fosse por sua liberdade, por isso ele é triste, oprimido. 
Ao refletir sobre a infelicidade humana, Espinosa (2005) declarou em 1674 que "o homem submete-se à servidão porque é triste, amedrontado e supersticioso, fatores que anulam sua potência de vida, deixando-o vulnerável à tirania do outro, em quem ele deposita a esperança de Felicidade" (ESPINOSA apud SAWAIA, 2006, p. 83). Essas reflexões influenciaram, posteriormente, as ideias de Marx, em 1844, ao discutir as relações de poder. (SAWAIA, 2006).

A partir desse modo de pensar e de conceber a relação entre o homem e a natureza, apresentado por Espinosa (2005) e pela discussão feita por Marx (1993), cerca de dois séculos depois, foi produzido no século XX modo de pensar a Educação Ambiental.

Esse paradigma fundamenta a Educação Socioambiental e caracteriza-se por uma educação política, no sentido de que reivindica e prepara os cidadãos para exigir justiça social, cidadania nacional e planetária, autogestão e ética nas relações sociais e com a natureza, enfatizando questões, como: "por que" "fazer o que" e "como fazer" (REIGOTA, 2003).

A Educação Socioambiental está, portanto, "impregnada da utopia de mudar radicalmente as relações que conhecemos hoje, sejam elas entre a humanidade, sejam entre esta e a natureza" (REIGOTA, 2003, p. 11). Para Medina (1996), a educação socioambiental é um processo que consiste em propiciar às pessoas uma compreensão crítica e global sobre o meio ambiente.

A partir dessa compreensão, os sujeitos vão poder elucidar problemas e desenvolver atitudes que thes permitam adotar uma posição crítica e participativa a respeito das questões relacionadas com a conservação e com a adequada utilização dos recursos naturais, visando à melhoria da qualidade de vida, à eliminação da pobreza extrema e do consumismo desenfreado e à construção de relações sociais, econômicas e culturais (MEDINA, 1996). Essas relações devem ser capazes de respeitar e incorporar as diferenças (minorias étnicas, populações tradicionais), as questões de gênero e a liberdade popular para decidir na busca de caminhos alternativos (MEDINA, 1996).

A corrente socioambiental tem ainda como um dos seus objetivos integrar o sujeito à natureza, tendo como pressuposto que os sujeitos fazem parte de um sistema que tem que andar em equilíbrio. Essa visão socioambiental pode influenciar o modo de pensar e agir em relação aos problemas socioambientais.

Essas duas categorizações de correntes de EA que foram apresentadas e discutidas acima serão utilizadas como categorias de análises dos resultados desta pesquisa.

\section{Metodologia}

O presente trabalho investigou as contribuições da inserção da EA na prática docente no curso de Licenciatura em Pedagogia de uma IES para a formação do professor como educador socioambiental. Nesse sentido, optamos por desenvolver um estudo de caso de caráter qualitativo no referido curso.

O estudo de caso é caracterizado como "uma investigação empírica que investiga um fenômeno contemporâneo dentro de seu contexto da vida real" (YIN, 2002, p.32). A referida pesquisa foi realizada no âmbito de um curso de Licenciatura Plena em Pedagogia em uma IES pública no Estado de Pernambuco. Os sujeitos do presente estudo foram nove professores do quadro de efetivos do curso. Os instrumentos e equipamentos que foram 
utilizados para a pesquisa foram: entrevista semiestruturada; diário de campo e Mp3; análise documental.

Para a construção dos dados foi realizada uma entrevista semiestruturada com todos os professores do Curso de Pedagogia que se dispuseram a participar da pesquisa, a qual foi gravada em áudio, com o objetivo de identificar os formadores que desenvolviam um trabalho sistematizado e planejado com educação ambiental dentro do Curso de Pedagogia

A escolha dos professores que teriam as sequências didáticas observadas pela pesquisadora partiu do princípio que o entrevistado tinha que, de alguma forma, desenvolver algum tipo de trabalho sistematizado, planejado, com educação ambiental, no componente curricular que lecionava no Curso de Pedagogia.

A partir dessa análise foram identificados dois professores com essas características e eles tiveram uma sequencia didática acompanhada e analisada. Para essas observações, fizemos uso de anotações em diário de campo e gravação em áudio, e analisamos essas sequências à luz do nosso referencial teórico. E para análise, foram adotados alguns dos pressupostos teóricos e metodológicos da análise de conteúdo de Bardin (1977). A análise do conteúdo pretende superar as dúvidas e enaltecer a compreensão de um texto por meio de regras para a fragmentação do mesmo. Essas regras são determinantes de categorias e devem ser homogêneas, exaustivas, exclusivas, objetivas e pertinentes, pois, fazer uma análise temática, consiste em descobrir os núcleos de sentido que compõem uma comunicação, cuja presença ou frequência podem significar alguma coisa para o objetivo analítico escolhido (BARDIN, 1977). De acordo com as ideias de Bardin (1997), neste trabalho adotaremos a análise categorial ou temática que é uma das dimensões da análise de conteúdo, a mais utilizada na análise das práticas docentes.

\section{Resultados e discussão}

Categoria: Educação Ambiental na prática pedagógica dos docentes do curso de Pedagogia

Quadro 1 - Prática de EA nas turmas de Pedagogia.

\begin{tabular}{|c|c|c|}
\hline \multirow{2}{*}{ Subcategorias } & \multicolumn{2}{|c|}{ Sujeitos } \\
\cline { 2 - 3 } & $\mathrm{P} 1$ & $\mathrm{P} 2$ \\
\hline EA Formativo-Interacionista & $X$ & $X$ \\
\hline Promotora da sensibilização dos discentes em relação à EA & $X$ & $X$ \\
\hline
\end{tabular}

Legenda- (x) unidade de análise

O quadro 1 apresenta as subcategorias relativas à análise de duas sequências didáticas: uma do componente curricular Metodologia do Ensino da Ciência I, lecionado por P1 e outro, do componente Geografia na Prática Pedagógica I, lecionado por P2. A escolha dessas duas sequências deu-se pelo fato dos professores relatarem, na entrevista, que trabalhavam com educação ambiental sistematicamente nos componentes que ministravam.

Subcategoria formativo-interacionista 
A subcategoria formativo-interacionista tem por objetivo apresentar e discutir uma perspectiva de formação docente voltada para a interação, seja entre aluno-professor, aluno-aluno ou ligada ao ensino de uma rede de conteúdos.

A sequência didática observada de $\mathrm{P} 1$, professora do componente curricular Metodologia do Ensino da Ciência I, inicia-se com a distribuição do texto "Alegoria da Caverna", baseado na parábola da caverna do filósofo Platão.

O texto distribuído pela professora relata a história em falas e imagens de um grupo de pessoas que vivia em uma caverna e avistava o mundo através de sombras. No decorrer da história, um componente deste grupo saiu da caverna e passou a enxergar o mundo sem essas sombras. Esse membro do grupo volta à caverna tentando convencer o restante do grupo sobre o fato de o que avistavam eram sombras.

O interessante deste trabalho que a professora P1 realizou com a turma, foi a oportunidade de refletir sobre o ensino/aprendizagem e sobre a quebra de paradigma no ensino das Ciências, pois esse texto oportuniza a fazer diversas reflexões, tais como: a ideologia que existe por traz de todo ensino, que, dentro do texto, pode ser representado pelas sombras, impedindo de vermos as coisas como elas realmente são: a relação homem natureza e o papel do professor frente ao ensino e aprendizagem.

Continuando o trabalho sobre o texto, a professora inicia um debate. Nesse, a aluna A1 pontua que: o texto traz a ideia do "homem como parte do meio ambiente". No momento, em sinal de acordo, algumas alunas fizeram uns gestos com a cabeça. Outra aluna (A2), toma a fala e diz: "vemos a importância do professor levar em consideração o conhecimento prévio, para tentar trabalhar com as sombras". Outra aluna (A3) pede a palavra:

[...] há uma ruptura de paradigma no ensino das Ciências. Com a instigação, vem a reflexão. A gente não aprende só. A gente ainda vê a vida através de sombras. Um exemplo disso é a universidade. A gente aprende e lê muitos textos que foram escritos por muita gente, lê sobre aprendizagem, sobre a teoria de Piaget. Na realidade lê o que alguém escreveu sobre a teoria de Piaget, mas não lê o próprio Piaget. (A3).

Na fala acima de $A 3$, houve uma quebra de paradigma com o ensino através da metodologia da investigação e essa modalidade de ensino leva à reflexão em relação ao próprio processo de aprendizagem. Para exemplificar a sua fala, usa o exemplo do ensino superior, afirmando que ainda se aprende através de sombras, pois o contato com os textos sempre são de autores que abordam um tema de um teórico e os alunos, em sua maioria, não têm contato com os textos do próprio teórico. A nosso ver, essa crítica levantada pela aluna é muito coerente, quando nos deparamos com os planos de ensino. A literatura usada em sua maioria aponta para autores que debatem teorias, não oportunizando os alunos a terem o contato com os textos fontes, dos teóricos.

A aluna, ao criticar com coerência o processo de ensino aprendizagem ao qual foi submetida, indica-nos uma possível contribuição do curso na formação de um sujeito crítico e reflexivo. Essas críticas feitas pela aluna foram oportunizadas pela professora no momento em que deu espaço para o diálogo na sala e debateu sobre o texto. Além disso, houve um apoio à fala da aluna por parte da professora, quando a mesma falou que:

O processo de ensino tem que contribuir para transformação (...). A alienação é você reproduzir um discurso que não é seu (...). Crie o seu discurso (...). Temos que romper com a alienação, inovar e, se eu não 
estou entrando em crise com as ideias instituídas, eu não estou inovando. Eu não estou inovado. (...) qual é a prática que vocês estão assumindo a partir dessa discussão? (...) $\bigcirc$ ensino de ciências só vai ter sentido se nos proporcionar uma alfabetização científica na qual eu possa compreender o processo. E podemos colocar isso em qualquer contexto, se for ambiental, e socioambiental. Temos que relacionar a cultura, a política, a ciência para compreender a atuação. Temos que compreender em suas muitas facetas. (P1).

Observamos no fragmento acima que o discurso da professora caminha para uma linha de abertura da fala dos alunos e da inovação da prática docente, a partir do momento em que o aluno é convidado a pensar sobre o seu próprio discurso. Podemos analisar no discurso de P1 a relação que ela faz com o ensino de ciências e a educação socioambiental. A sequência didática de $\mathrm{P} 2$ vai pelo mesmo caminho de $\mathrm{P} 1$, que é de reflexão, de possibilitar o aluno a refletir.

A sequência didática observada de P2 é uma aula passeio. Inicia-se com P2 organizando os estudantes no ônibus. Após isso, ele faz uma explanação sobre o roteiro de atividades e explica aos alunos o que vai ser visto em cada ponto de parada do roteiro, como também fala um pouco sobre como vai ser a avaliação das atividades que foram solicitadas.

São estas as atividades solicitadas aos alunos: em dupla, fazer um relatório de vivência da aula e fazer uma entrevista com três (3) moradores das comunidades ribeirinhas que perderam parentes ou casa nas enchentes. As comunidades visitadas foram: Branquinhas, em Alagoas, que teve $70 \%$ da cidade tomada pelas águas do rio, e Palmares, em Pernambuco, que também teve $50 \%$ da cidade tomada pelo rio. Ao sair da universidade, o P2 faz uma parada em Lagoa Encantada, um bairro popular que fica localizado na periferia do Recife, o professor solicita aos alunos que observem a paisagem e digam para a turma o que veem.

P2 - Gente, antes de mais nada, o que vocês observam nesta paisagem?

Aluno 1 - Uma zona superpopulada.

P2 - (...) Esse ponto é Lagoa Encantada, Zona Sul da Cidade do Recife. Nessa área, há um forte adensamento populacional. (...) Uma característica dessa área é uma área popular e há questão também da permanência dos filhos próximo aos pais. Então, há uma verticalização das residências. Essa é uma das causas do aumento das residências.

P2 começa a explicar a formação das comunidades populares junto aos morros, que é um local impróprio para moradia, depois da explicação do aumento de moradias nessa região. P2 introduz a questão da EA, aliada à Geografia:

Nessa área, são ocorrentes eventos naturais, que são frequentes durante eventos chuvosos. Eles são de duas ordens: via alagamentos e via movimentos de massas, que a gente chama de deslizamento de terra. Ali em cima, você tem o que a gente chama de formulação de barreiras, mas na verdade é uma encosta. (...). É nessa área de topo que normalmente a ocupação se dá de forma desordenada. Já, uma vez, sem a devida gestão por parte do poder público, é o que acontece: essas áreas sofrem processos de erosão e de movimentos de massas. Nós observamos que algumas áreas das encostas, onde você tem cobertura vegetal e outras, as 
coberturas desaparecem. E é nesse lugar justamente onde você tem movimentos de massas e consequentemente movimentos de terra. (...) $\mathrm{E}$ lá embaixo você tem um rio, acho que é um afluente o rio Jordão, que é uma área de baixada. Inclusive o próprio nome do bairro, Lagoa Encantada, pois existia uma lagoa nessa região que foi aterrada devido ao processo de ocupação e, consequentemente, quando tem as chuvas nessas regiões, há um recorrente processo de alagamento. Aí você tem a encosta desnuda e as encostas que foram totalmente concretadas. Vejam os canos saindo para vazão da água. Aí vem aquela velha questão: você resolve um problema, contendo os movimentos de massa, e, em contra partida, você causa outro problema, o aquecimento na área. O concreto logicamente vai emanar um calor bem maior que a cobertura vegetal natural. A cobertura do solo ou vegetal que deveria existir, daria certo alívio na área, porque você tem um processo de evácuo-transpiração, que vai emitir a umidade que dá certo conforto térmico e, com esse paredão de concreto, você tem o aquecimento dessa região. Por um lado, você corrige a questão do movimento de massa e, em contra partida, você vai incentivar o aquecimento. Outro aspecto negativo ocorre quando chove, a água iria naturalmente se infiltrar no solo, iria escoar na encosta. Ela seria absorvida. Nesse caso do concreto, não. A água rapidamente vai escoar, o paredão é um fator que ele, nada mais nada menos, propiciou uma efetivação do escoamento artificial rápido da água. Então, uma das causas das inundações lá embaixo é justamente essa. A água, quando desce no solo, não infiltra, não penetra. Ela rapidamente vai escoar e vai escoar para a parte de baixo. Esse processo, esse tipo de gestão do Poder Público, para minimizar o efeito de risco, leva ao desencadeamento de outros, justamente a questão de aprimorar o processo de alagamento dessa região devido à falta de infiltração da água, necessária. Essa água cai lá embaixo e vai para o rio, proporcionando o alagamento de outras áreas. Aqui você tem um bom exemplo dessa chamada ocupação desordenada. (P2).

Nesse trecho de fala, P2 explica a complexidade da questão ambiental, pois, ao trazer um conteúdo específico da Geografia, que é ocupação desordenada, ele faz uma rede de relações socioambientais. Primeiro, ele apresenta aos alunos um bairro já conhecido por eles e pergunta sobre a percepção deles sobre esse bairro. Após essa primeira parte, P2 explica sobre a formação desse bairro em um lugar impróprio, e o porquê esse bairro está crescendo e as consequências socioambientais desse crescimento.

P2 faz uma explanação para os alunos de uma cadeia de acontecimentos a partir da ocupação de uma área de morro. Ele explica que, para ocupar essas áreas, os moradores retiram a cobertura vegetal dessas áreas e, sem essa cobertura, acontecem os deslizamentos, provocando até mortes. P2 explica que, para conter esses deslizamentos, o poder público, ao invés de replantar, faz uma cobertura de concreto nos morros, provocando um superaquecimento e inundações, uma vez que as águas da chuva não infiltram com facilidade no concreto. Outro ponto muito interessante levantado por P2 é a questão do aterramento do rio, para construção de casas nas áreas de baixadas. Além disso, P2 faz uma relação desses acontecimentos com poder público. Nesse trecho de fala, P2 apresenta a complexidade da educação socioambiental e como um acontecimento de ordem natural, como a chuva, por exemplo, pode se reverter em um acontecimento 
socioambiental, pois o simples fato de chover desencadeou uma série de acontecimentos calamitosos ocasionados pelo mau uso dos recursos naturais.

No caso, o solo, quando da ocupação desordenada dos morros, sofreu com a retirada da cobertura vegetal e concretização; o rio, quando do crescimento da ocupação populacional, foi aterrado. Esses exemplos reais, apresentados aos alunos de Pedagogia, demonstram a importância de se trabalhar a EA. Se as pessoas, de modo geral (isso inclui todas as esferas da sociedade; governo; empresas; associações; organizações nãogovernamentais), tivessem um comprometimento socioambiental, é certo que não teríamos tantos problemas com os eventos de ordem natural, como a chuva e a seca, pois estaríamos caminhando em parceria com a natureza.

Por isso reforçamos a importância dessas aulas de P1 e P2 e comprovamos que os futuros professores tiveram a oportunidades de, na sua formação, discutir e refletir sobre as questões socioambientais.

\section{Subcategoria promotora da sensibilização dos discentes em relação à EA}

Essa subcategoria denominada visão promotora da sensibilização dos discentes em relação à EA tem por objetivo apresentar e discutir uma perspectiva de formação docente voltada para a sensibilização dos discentes em relação à EA.

Apresentaremos a seguir a análise e discussão de duas sequências didáticas dos professores $\mathrm{P} 1$ e P2, os quais se enquadram na categoria apresentada acima.

P1, no momento final do debate da primeira aula da sequência didática, propôs para os alunos, como tarefa para a aula seguinte, assistir ao filme História das Coisas e ler a transcrição do filme. A professora explica que esse filme conta a história do consumismo e a influência da mídia na aquisição de coisas de que não precisamos. Explica também que essa transcrição do filme foi feita pelo seu grupo de EA. Finaliza a sua fala dizendo que "antes de pensarmos em qualquer questão de Metodologia do Ensino das Ciências, temos que pensar na nossa concepção do Ensino das Ciências" (P1).

Na continuidade da sequência didática, a P1 inicia a aula solicitando que a turma forme grupos para debater sobre o que foi visto no filme "História das Coisas", pontuando os tópicos que considerassem mais importantes, relacionando-os com o Ensino das Ciências.

Após os grupos pontuarem os tópicos mais relevantes, P1 promoveu um debate, objetivando a socialização das ideias dos grupos. Os alunos destacam vários tópicos. Entre eles estão a crítica ao consumismo, a mídia como instrumento de manipulação do governo, a exploração de mão de obra barata, a falta de consciência das questões socioambientais, e a relação que há entre o ensino de ciências e a EA. Destacamos a fala de algumas alunas no desenvolvimento deste trabalho:

Podemos perceber que esse filme traz uma crítica muito forte ao consumismo. (A1).

Eu senti que, em relação às questões ambientais apresentadas no vídeo, a mídia está diretamente envolvida, pois ela incentiva o desperdício e o consumo desnecessário. Além disso, tem a questão do governo, pois ele manipula o custo de produção, sem contar com os grandes empresários, que manipulam a carência de empregos. É um grande sistema que só beneficia a poucos e compromete o bem estar de muitos. (A2).

O ensino de ciências está relacionado com essas questões ambientais, o ensino como um todo. (A3). 
Eu vejo essas questões ambientais ligadas à relação de poder. As pessoas hoje em dia são respeitadas pelo que elas têm. Há uma grande homogeneização da identidade pelo que a pessoa tem. E o ensino de ciências pode contribuir para uma reflexão sobre a nossa relação com o meio ambiente, em relação aos aspectos atitudinais. (A4).

Temos que ensinar o povo a exigir o que é melhor para a gente. (A5).

No ensino das ciências temos que apresentar tudo que está relacionado com, ou por trás das questões ambientais, pois o ensino é uma ponte para a mudança. (A6).

Vimos nesse vídeo, o planejamento das coisas. Que esse consumismo e destruição da natureza é algo planejado. Esse vídeo nos faz pensar na relação do homem com o meio. Temos que pensar em formar cidadãos para exigir mais, e o ensino de ciências pode e deve contribuir para formação desse cidadão, e a escola tem um papel na formação. (A8).

Temos que ter consciência que temos que cuidar do planeta para as próximas gerações. O professor pode trabalhar, desde a educação infantil, as questões ambientais e assim, contribuir para a melhoria da relação homem-natureza. É nesse ponto que o ensino de ciências pode nos ajudar com esse trabalho. (A9).

Pois, com a leitura da transcrição do vídeo, percebi que eu sou estragada, que consumo a mais da conta, que desperdiço muitas coisas que ainda estão boas. E esse vídeo nos faz refletir sobre nossa prática. Pensei até em fazer uma sequência didática trabalhando o dia a dia para questões ambientais. Como somos influenciados, a todo momento, pelos meios de comunicação, para o consumo. Pensei em levar isso para os meus alunos. (A10)

Percebemos nos trecho de falas das alunas que, de alguma forma, a atividade proposta por P1 provocou nas discentes o pensar sobre suas atitudes socioambientais. Essa atividade de ver o filme "História das Coisas" e discutir sobre os aspectos socioambientais apresentados no filme contribuiu para uma sensibilização socioambiental dos discentes. Isso fica nítido na fala das alunas, como, por exemplo, na fala de A8, "Vimos nesse vídeo [...] que esse consumismo e destruição da natureza é algo planejado. Esse vídeo nos faz pensar na relação do homem com o meio. Temos que pensar em formar cidadãos para exigir mais". Atividades como essa de P1 devem ser feitas no curso de formação, pois é vista sua eficácia no que se refere a sensibilizar os discentes a refletir sobre as questões ambientais.

Da mesma forma que a sequência didática de P1 possibilitou a sensibilização ambiental através de um processo de reflexão dos discentes, P2 também fez o mesmo, na sua aula de campo.

O segundo ponto visitado pela turma foi Palmares. No local, P2 explicou que o Poder Público estava fazendo a mesma coisa que fez na Região Metropolitana, retirando as pessoas das áreas sujeitas a alagamento, colocando-as em região de morros. Esse segundo ponto teve, no ano de 2010, uma grande enchente que destruiu boa parte da cidade. Pessoas morreram e muitas outras ficaram desabrigadas. A cidade declarou estado de calamidade pública.

Estamos aqui agora no município de Palmares. Aqui seria o que a gente denomina médio curso do rio Una. Essa região foi afetada por uma 
enchente. A última foi no período de 16 a 18 junho de 2010 (...) Essa área é uma área sujeita a risco de inundação em decorrência da existência do rio. Logicamente, em decorrência de vários aspectos ao logo do canal e margem, em períodos de enchentes, há rapidamente a subida do rio e, consequentemente, esses eventos de inundações (...). Choveu em toda a bacia. Esse sistema causou essa inundação intensa na região e logicamente colocou muitas pessoas sob risco. Aí vem o conceito de risco: o que é risco? Risco é justamente quando um grupo de pessoas, ou uma pessoa, está em uma área sujeita a determinado evento natural, como é uma enchente. Mas para propor um risco, é necessário que existam pessoas nessas condições. Aí vem outro conceito: de vulnerabilidade. Só existe risco quando há vulnerabilidade a determinado evento. Então, quem mora ao logo de um rio, logicamente está vulneral a enchentes. (...) a gente vai ver ao longo do canal, onde ocorreu o evento com mais magnitude, nas áreas residênciais. (P2).

P2 nesse momento explicou à turma o que foi esse evento de enchente de 2010. As causas físicas, geológicas e sociais fizeram esse evento ter proporções devastadoras. $\bigcirc$ fato de levar os estudantes ao local no qual aconteceu esse evento promoveu um olhar diferenciado, um olhar mais sensível sobre a questão socioambiental. Os estudantes puderam ver de perto as consequências da falta de planejamento socioambiental, pois uma das causas desse evento natural ter proporções grandes de destruições e mortes foi a falta de sensibilização e percepção socioambiental por parte da população ribeirinha e do governo.

Em seguida, P2 explica que as casas que ficam perto dos morros estão sendo erradicadas. P2 explica para os alunos sobre a importância da preservação da vegetação natural na margem ligando os conceitos da Geografia aos da EA.

Então, essas áreas construídas estão sendo erradicadas. A gente percebe o outro lado da margem, uma passagem típica de uma margem fluvial. Com vegetação que está protegendo o rio, bambu. Essa vegetação tem o papel de dar sustentação ao sol. Aí, as raízes da vegetação ao longo da margem têm uma ação de segurar o solo. Então, no período de chuvas e de enchentes, essa vegetação vai fixar-se no solo e consequentemente vai amenizar o efeito de erosão e de assoreamento do rio. Assim, quanto mais o rio está assoreado, mais corre o risco de inundação, porque, onde deveria ter água, tem sedimento e, quando vem uma tromba d'água, é uma onda que vem de médio ao baixo curso do rio, essa água vai extravasar e vai logicamente inundar. A mesma coisa ocorre em área que tem ocupação, numa área que deveria ter vegetação. Então, em vez da vegetação estar absorvendo água, na falta dela, essa água está escorrendo diretamente para o canal. É a mesma coisa que vimos em Recife. Essa ocupação à margem do rio é mais um contribuinte ao processo de inundação. Isso é comum. A enchente é um processo natural de um rio. Então, a cada dois anos, cinco anos, dez anos, você tem uma recorrência do evento. Então, ocupar o rio traz um risco, porque você pode até ocupar, passa um ano, dois anos, cinco anos sem nenhum evento, e você pensa não tem problema. Não, mais cedo ou mais tarde, você terá uma enchente. Então, a vulnerabilidade está atrelada à incredulidade por parte do indivíduo em relação aquilo: não vai acontecer. Isso não é uma coisa específica de brasileiro? Não; isso só não acontece 
no Brasil? Não. Já vi artigos no Canadá: o povo ocupa áreas de avalanches; nas Filipinas, lá o povo também ocupa os canais. $O$ fato está atrelado à falta de terra para a populaçã; a questões de relações sociais; a questões de relação de trabalho; a questão da população não poder comprar um terreno, não poder alugar, não poder comprar uma casa. Então, vai se submeter a morar em uma área arriscada. Então, é o lócus que sobrar. Eles estão ali, mas estão cientes do risco. "Ah! Eu vou fincando até onde der", até porque há por parte do Estado "uma permissão" (entre aspas) de que seja construído e seja mantido até chegar a um ponto como esse. Tinham que retirar e retiram, e agora estão ocupando ali. Vejam as novas casas lá em cima do morro. Aí saem do alagamento e agora estão sujeitos a processos erosivos e de movimento de massa no futuro. Poderiam construir em área alta, mas eles estão muito próximos do topo da área. Logicamente, a dinâmica natural, aquele pessoal vai construir calçadas, vai impermeabilizar o solo. Logicamente, o escoamento vai aumentar, vai descer pela encosta e vai desencadear outro processo, erosivo ou de movimento de massa, outro risco que eles vão se colocar. (...) Vejam ali, onde não tem preservação. A água desce pela encosta. Aí abriu um lasco, que é que a gente chama de voçoroca. Então, colocaram ali uns sacos de areia que são para coibir a descida da água. Estão vendo aquela escada lá no morro perto dos sacos de areia? Ali é um dissipador de energia. A água, quando desce por aqueles degraus, vai perdendo energia até chegar ao nível de base. Veja que o canal não está com a vegetação natural. Ali, veja você que o canal foi concretado, que também não é uma boa ideia. O ideal é manter a margem com a vegetação, porque você mantém a dinâmica do rio natural. Com o concreto, a água passa rapidamente e não tem infiltração também. (P2).

P2 em seu discurso oportuniza a sensibilização dos estudantes; chama a atenção deles para a importância de manter a vegetação natural. P2 demonstra, no seu discurso, uma politização. Ao tratar das questões ambientais, enfatiza a responsabilidade do poder público no processo de desmatamento e nas ocupações inapropriadas.

\section{Considerações finais}

Percebemos que, no decorrer das atividades práticas e teóricas das sequenciais didáticas ministradas por P1 e P2, foram oportunizadas aos estudantes reflexão socioambiental e prática reflexiva, que vai em direção a defendida por nós e por Gadotti (2005), Loureiro (2004), Pimenta (2004), Reigota (2003), Tardif (2002), Freire (2002), Sucena (1998), Medina (1996) e Nóvoa (1995).

Identificamos que as sequencias didáticas ligadas às disciplinas de ciências e a geografia no curso de Pedagogia possibilitou aos seus estudantes, a oportunidade de refletir criticamente sobre as questões socioambientais, contribuindo para a formação de um pedagogo com um olhar mais sensível à EA.

O processo formativo que os professores formadores do Curso de Pedagogia vêm desenvolvendo em relação à EA, revela que há uma preocupação por parte dos professores formadores em promover uma formação voltada para a sensibilização ambiental e para a 
interação, seja entre aluno-professor, aluno-aluno ou interação ligada ao ensino de uma rede de conteúdo.

\section{Referências}

BARDIN, L. Análise do conteúdo. São Paulo: Martins Fontes, 1977.

BERMAN, M. The renchanment of the world. Ithaca: Cornell University Press, 1985.

CAPRA, F. A teia da vida: uma nova compreensão científica dos sistemas vivos. São Paulo: Cultrix, 2006a.

CAPRA, F.et al. Alfabetização ecológica: a educação das crianças para um mundo sustentável. São Paulo: Cultrix, 2006b

CARVALHO, I. C. M. A invenção ecológica: narrativas e trajetórias da educação ambiental no Brasil. 2. ed. Porto Alegre: UFRGS, 2002.

CARVALHO, I. C. M. Educação ambiental: a formação do sujeito ecológico. São Paulo, Editora Cortez, 2004. (Coleção Docência em Formação).

DESCARTES, R. Discurso do método [comentários: Denis Huisman]. Brasília: UnB, 1998.

DESCARTES. Descartes. São Paulo: Editora Nova Cultura, 1996. 431p. (Coleção os Pensadores).

ESPINOSA, B. Ética demonstrada à maneira dos geômetras. [tradução: Jean Melville]. São Paulo: Martin Claret, 2005.

FERREIRA, M. L. R. A dinâmica da razão na filosofia de Espinosa. Fundação CalousteGulbenkian / Junta Nacional de Investigação Cientista e Tecnológica, 1997.

FREIRE, P. Pedagogia da Autonomia: saberes necessários à prática educativa. 25. ed. São Paulo: Paz e Terra, 2002. (Coleção Leitura).

GADOTTI. M. Pedagogia da terra e cultura de sustentabilidade. Revista Lusófona de Educação, no 6, ISS1645-7250. Universidade Lusófona de Humanidades e Tecnologia, Lisboa, Portugal,2005.

GRÜN, M. Descartes, historicidade e educação ambiental. IN: CARVALHO, I; GRÜN, M. e TRAJBER, R. (Org.) Pensar o Ambiente: bases filosóficas para Educação Ambiental. Brasilia: Mistério da Educação, Secretaria de Educação Continuada Alfabetização e diversidade. UNESCO, 2006. ISBN 85-98171-70$0,244 p$.

GRÜN, M. Hermenêutica, Biorregionalismo e Educação Ambiental. In: SAUVÉ, L.; ORELLANA, I.; SATO, M. (Dir.) Sujets choisis en éducation relative à l'environnement: d'une Amérique à l'autre. Montréal: ERE-UQAM, 2001.

GUIMARÃES, M. Educação Ambiental Crítica. In: BRASIL. Identidades da educação ambiental brasileira. Brasília: MMA, 2004.

LOUREIRO, C. F. B. (Org.). Cidadania e meio ambiente. Salvador: Centro de Recursos Ambientais, 2003.

LOUREIRO, C. F. B. Trajetória e fundamentos da Educação Ambiental. São Paulo: Cortez, 2004.

LOUREIRO. F. Karl Marx: história, crítica e transformação social na unidade dialética da natureza. IN: CARVALHO, I.; GRÜN, M. e TRAJBER, R. (Org.) Pensar o ambiente: bases filosóficas para Educação Ambiental. Brasília: Mistério da Educação. Secretaria de Educação Continuada Alfabetização e diversidade. UNESCO 2006. ISBN 85-98171-70-0, 244 p. (Coleção Educação para Todos; V.26).

MARCELO, C. G. Formación del profesorado para el cambio educativo. 2 ed. Barcelona: EUB, 1995. 
MARX, K. e ENGELS, F. A ideologia alemã [Trad. Luiz Cláudio de Castro e costa]. 3 ed. São Paulo: Martins Fontes, 2002.

MARX, K. Manuscritos econômico-filosóficos. [Trad. Jesus Ranieri]. São Paulo: Boi- tempo, 1993.

MARX, K. O Capital: crítica da economia política. Livro I- O processo de produção do Capital. V.1. [Trad. Reinaldo Sant'Ana].23 ed. Rio de Janeiro: Civilização Brasileira, 2006.

MEDINA, N. M. Elementos para a introdução da dimensão ambiental na educação escola - $1^{\circ} \mathrm{grau}$. IN: Amazônia: uma proposta interdisciplinar de educação ambiental. Brasília: IBAMA, 1994.

MINAYO, M. C. S. O Desafio do conhecimento: pesquisa qualitativa em saúde. 7. ed. São Paulo: Hucitec, 2000.

NÓVOA, A. Formação de professores e profissão docente. In: NÓVOA, A. Os professores e a sua formação. (Org.) Lisboa: Dom Quixote, 1995b, p. 15-33.

OLIVEIRA, V. F. de. Espaços e tempos produzindo um professor. UNIrevista, v.1, n.2, abr. 2006. Disponível em: <http://www.ufsm.br/gepeis>. Acessado em: 10 set. 2010.

PERRENOUD, P. A Prática reflexiva no ofício de Professor: profissionalização e razão pedagógica. Tradução de Cláudia Schilling. Porto Alegre: Artmed Editora, 2002.

PERRENOUD, P. Dez novas competências para ensinar. Porto Alegre: Artmed, 2000.

PIMENTA, S. G. e GHEDIN, E. (Orgs.). Professor reflexivo no Brasil: gênese e crítica de um conceito. São Paulo: Cortez, 2002.

REIGOTA, M. Meio Ambiente e Representação Social. 3. ed. São Paulo: Cortez,1998.

REIGOTA, M.; POSSAS, R.; RIBEIRO, A. (Orgs.). Trajetórias e narrativas através da Educação Ambiental. Rio de Janeiro: DP\&A, 2003.

SANTOS, J, P. OLIVEIRA, G, F. Concepções e Práticas de educação ambiental: o que pensam alguns docentes do ensino fundamental. VIII ENPEC - Encontro Nacional de Pesquisa em Educação em Ciências e CIEC - Congreso Iberoamericano de Investigación em Enseñanza de las Ciências. Anais...Campinas: Unicamp, 2011.

SANTOS, J, P. OLIVEIRA, G, F. Narrativas dos professores de ciências sobre educação ambiental: concepções e práticas. Disponível em: <http://www.educonufs.com.br/vcoloquio/cdcoloquio/ cdroom/eixo\%204/conteudo.htm>. Acesso em 02 jan. 2012.

SAVIANI, D. História das Ideias Pedagógicas no Brasil. São Paulo: Autores Associados, 2007.

SAWAIA, B. B. Espinosa: o precursor da ética e da educação ambiental com base nas paixões humanas. In: CARVALHO, I. C. M. de; GRÜN, M.; TRAJBER R. (Org.). Pensar o Ambiente: bases filosóficas para a Educação Ambiental. Brasília: Ministério da Educação. Secretaria de Educação Continuada, Alfabetização e Diversidade. UNESCO, 2006. ISBN 85-98171-70-0, 244p. 